traits is due to an excessive dilation of the eye-pupils caused by the low light intensity prevailing when the portrait was taken. By focusing under a light whose intensity approaches that of weak daylight, the eye-pupils assume their natural size and a natural expression is thereby obtained.

\title{
STELLAR IMAGES ON A PHOTOGRAPHIC PLATE AS AFFECTED BY DEVELOPMENT.'
}

\author{
By F. E. Ross.
}

[ABSTRAÇT.]

A Preliminary investigation of a two-fold nature: $(a)$ determination of differences in power, if any, of various developers in developing faint stellar images; $(b)$ determination of differences in quality, if any, of stellar images, depending upon the developer, with special reference to the accuracy of measurement of their distance apart on the plate.

The tests were made by photographing a series of small, round holes in a plate. Under $(a)$ above, no certain differences were detected. In investigating (b) pyro and caustic hydrochinon (process developer) were tried, development being carried to two and four minutes. From the measurement of 320 distances between images it was establishd that greater accuracy in measurement was secured where the process developer was used; that the lighter development gave best results. This superiority was anticipated, since the appearance of the images was decidedly better for short development in process developer than for any other of those tried.

THE FUNDAMENTAL SCALE OF PURE HUE AND RETINAL SENSIBILITY TO HUE DIFFERENCES.?

\section{By L. A. Jones.}

[ABSTRACT.]

WHEN radiant energy is incident upon the retina of a normal eye the sensation of light is produced. This sensation may be said to consist of two factors, brightness and color, the former

${ }^{1}$ Communication No. 47 of the Research Laboratory of the Eastman Kodak Company, published in Journal, Optical Socicty of America, January, I9i7.

${ }^{2}$ Communication No. 44 of the Research Laboratory of the Eastman Kodak Company, published in Journal, Optical Society of America. January. I9I 7. 
being dependent upon the intensity and the latter upon the quality of the incident radiation. The quality of the radiation may be specified by stating its wave-length, in case radiation of but one frequency is present; or, in case it is composed of a mixture of many frequencies, by stating the wave-length and intensity of each of the component elements. The curve representing the relations existing between the intensity and wave-length of such mixed radiation, commonly called a spectrophotometric curve, is usually plotted with intensity factors as ordinate and wavelengths as abcissa values.

Such a curve constitutes a complete physical specification of the quality of the radiation, and hence of color. The retina, however, being a synthetic rather than an analytic receiving organ, does not recognize the individual component parts of the radiation as such, but receives the mixed radiation as a single stimulus producing a single color sensation. Hence a spectrophotometric curve, while entirely satisfactory from a physical or objective standpoint, does not constitute a physiological specification of the color of the visible radiation, and it is necessary to provide other means for the satisfactory specification of color as such.

Subjectively - that is, from the standpoint of the subjective sensation-color may be said to consist of two factors, hue and purity or saturation. Hue refers to the position in the spectrum of the dominant quality, while purity expresses the extent to which the color departs from the condition of monochromatism. The factors, hue and purity, can be measured directly by color molyzing instrument of the monochromatic type.

It is evident, then, since hue must be expressed in terms of the wave-length of the radiation, that, if a hue scale is to be established, the points on that scale must be designated in wave-length units. The first requirement of a scale for the measurement of any quantity is that the unit used shall be of a fixed magnitude and of the same value throughout the scale. It has been found, however, that equal wave-length differences do not produce equal color sensation differences throughout the sensation scale being considered. Hence the wave-length unit is not suitable for use as a unit in the establishment of a scale of subjective color sensation.

It seems to be most logical, therefore, and in fact the only alternative, to adopt as the unit for such a scale the least percepti- 
ble color sensation difference, and to assume that this sensation unit (difference limen) is equal at all points in the sensation scale. The question as to whether or not the difference limen is equal at all points on any sensation scale has been discussed at great length by philosophers and psychologists, and seems to be capable of settlement in either direction by the proper course of metaphysical reasoning. However, from the standpoint of a physicist, it seems entirely reasonable to make the difference limen at all points on a sensation scale equal by definition and to adopt

FIG. 1 .

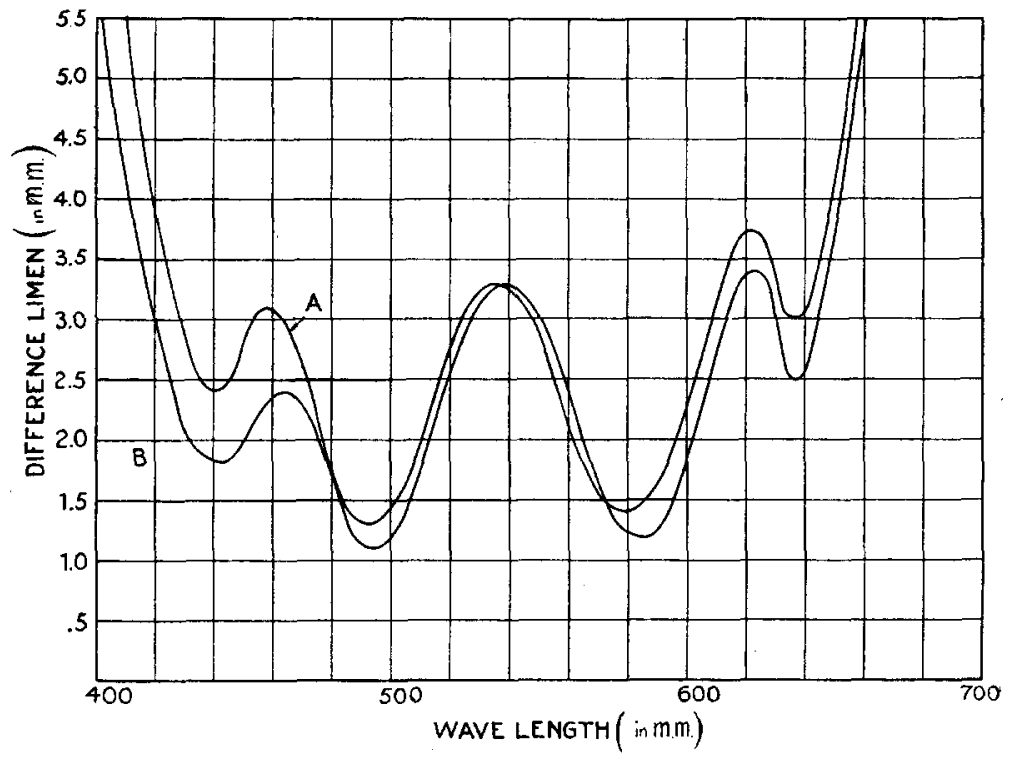

this least perceptible difference as a sensation unit and to use it for the establishment of sensation scales.

The first step, then, in the establishment of the fundamental hue scale is the determination of precise values (in terms of wave-length units) for the average normal human eye of the least perceptible hue differences (the sensation unit) throughout the visible spectrum. The final values, then, must be the result of the proper summarization of a large amount of data obtained from the study of a large number of different individuals having normal vision. 
Steindler ${ }^{1}$ has made measurements on the hue sensibility of twelve subjects, all having normal color vision. It seemed desirable to obtain further data on difference limen of other individuals, and for this purpose the following work was carried out. The measurement of the required difference limen involves the measurement of the difference in the wave-length of the light illuminating two fields which appear just perceptibly different in hue; since the desired scale is that of pure hue, fields illuminated by light as nearly monochromatic as possible must be used. Hence apparatus giving very pure monochromatic light of easily measurable and variable wave-length in connection with some type of two-part photometer field, each part of which may be illuminated independently by monochromatic light of variable quality and intensity, must be employed. It is very important that the intensity be easily controllable, for in making a judgment of equality or difference of hue it is necessary to maintain an intensity balance between the two fields in order that the judgment of hie may not be influenced or confused by the existence of an intensity difference. The first instrument constructed for the fulfilment of these conditions is shown diagrammatically in Fig. 3 .

The determination of the difference limen was accomplished by adjusting the angular positions of the two collimating systems, $\mathrm{O}_{1} \mathrm{~L}_{1}$ and $\mathrm{O}_{2} \mathrm{~L}_{2}$, until a just perceptible difference in hue was apparent between the two portions, $a, a^{1}$ and $b$, of the photometric field, and by then obtaining the wave-length difference from readings taken from the calibrated scales, $B_{1}$ and $B_{2}$. The value thus obtained gave the difference limen for a point in the spectrum midway between the two wave-length values read from the calibrated scales. Several readings were made at each point and at many different points throughout the visible spectrum, a difference limen-wave-length curve being plotted from the values thus obtained.

Many data were obtained with this instrument, which in many ways was found to be very satisfactory, but, due to certain mechanical defects, this was discarded and the work continued with improved apparatus. This consisted of a Brace spectrophotometer used in connection with a Hilger spectroscope of the constant-deviation type. This arrangement permitted of much higher

${ }^{2}$ Steindler, O., Ak. Wiss. Wien., I1 5 IIa Jan., Igo6. 
precision in the measurement of the wave-length of the light illuminating the two parts of the photometric field at any time, and also made it possible to set the two fields to an exact color match by means other than the visual judgment of hue.

In Fig. 5 are shown two complete limen curves, curve $A$ being plotted from data obtained with the first instrument and curve $B$ from limen data taken with the Brace-Hilger apparatus. These curves agree very well in shape and in magnitude of the limen values. They also agree quite well with Steindler's mean curve

FIG. 3.

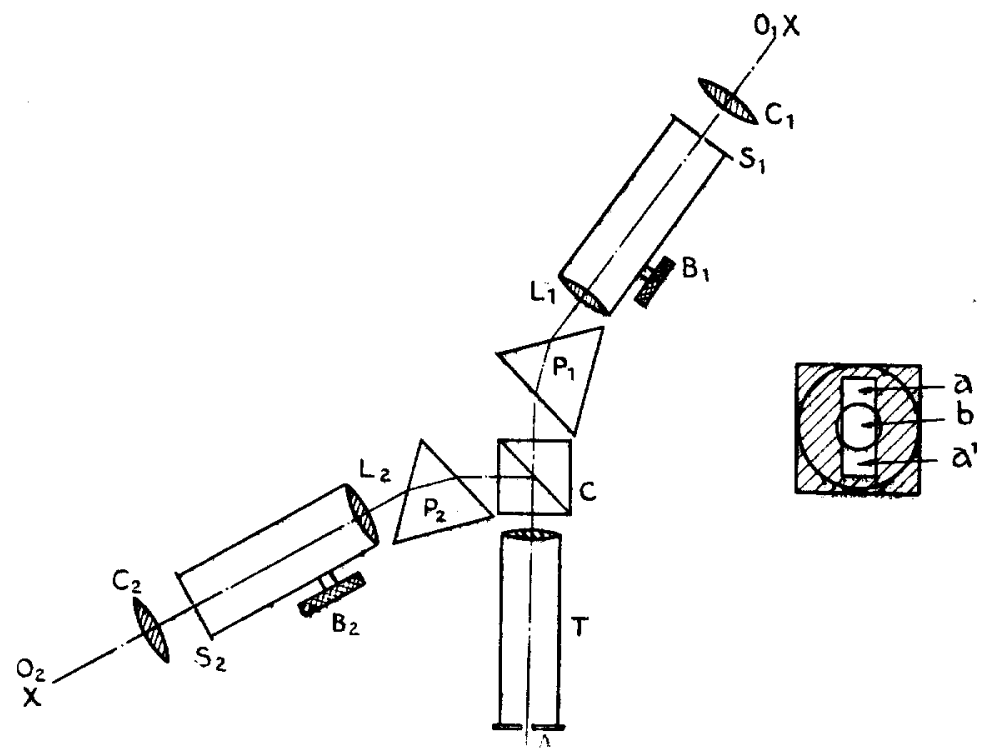

(Fig. I), showing the same typical maxima and minima. The limen values agree fairly well with those of Steindler except in the blue end between $400 \mu \mu$ and $470 \mu \mu$. This lack of agreement will be mentioned again later in the discussion.

The mean curve obtained by averaging the three sets of data obtained with the right eye is shown as curve B, Fig. I, in order that its shape and the magnitude of the limen values may be easily compared with the mean of Steindler's data. It will be noted that the values of curve B agree very well with those of A from about 470 to $580 \mu \mu$, and that in the red and yellow from 580 to 660 the curve $B$ shows limen values only slightly less than those of $\mathrm{A}$. In the blue end, however, from 4 Io to 470 the limen 
values of $B$ are considerably less than those of $A$. The positions in the spectrum of the various maxima and minima are nearly the same in the two curves.

The results so far indicate that an observer can repeat results on hue limen fairly well, and that the limen-wave-length curve for an individual has a very definite shape.

Now, referring to the scale reading curve, plotted from these same values, in Fig. 6, suppose that a series of points separated by equal intervals be laid off on the hue scale ( $y$ axis) and a series of horizontal lines be drawn through these points cutting the scale-reading curve. Now the wave-length values obtained by projecting these points of intersection on the wave-length axis

Fig. 5 .

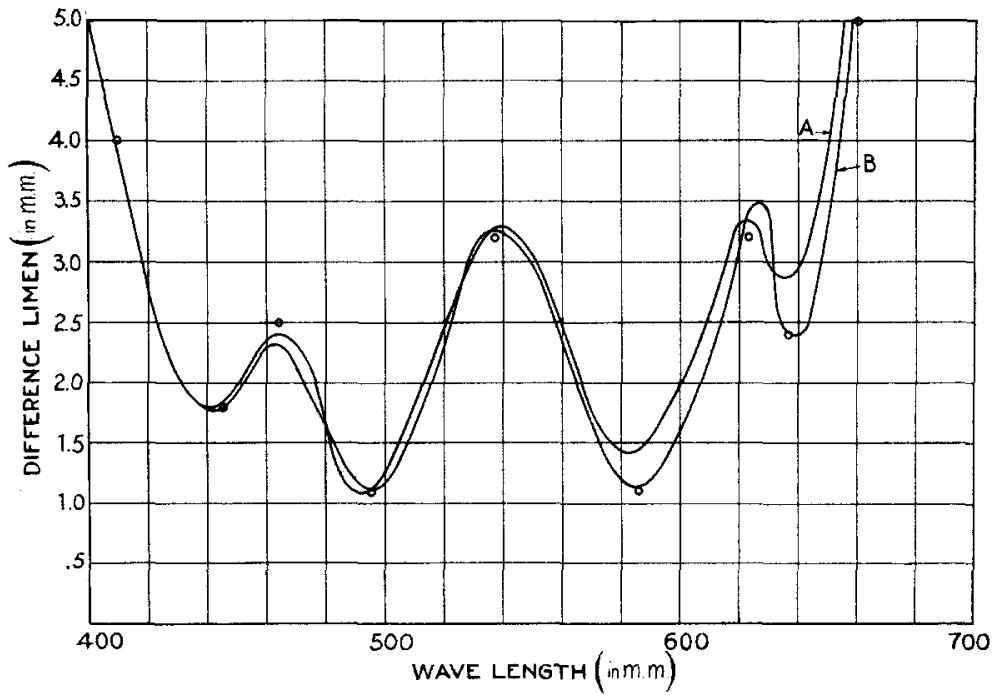

( $x$ axis) will represent a series of spectral hues separated by equal sensation steps. Or, by the inverse process, starting with the wave-length values, it is easy to determine whether any series of hues are separated by equal or unequal sensation steps.

This method of analysis has been applied to one of the best systems of color standards. This system was devised and worked out by Robert Ridgway, Curator of the Division of Birds, United States National Museum, and is described in detail and illustrated with II 5 named color standards in his book, "Color Standards and Nomenclature." The system is based on the correct princi- 
ple of adopting both hue and purity scales based on equal sensation intervals. The scale of pure (spectral) hue consists of 30 units in the visible spectrum, separated by equal sensation intervals, and 6 units spaced through the purples (not present in the spectrum).

In order to determine the spacing on the sensation scale of these $3^{6}$ hue scale units, it was necessary to measure the dominant hue of each. The actual samples used were cut from sheets ob-

FIG. 6.

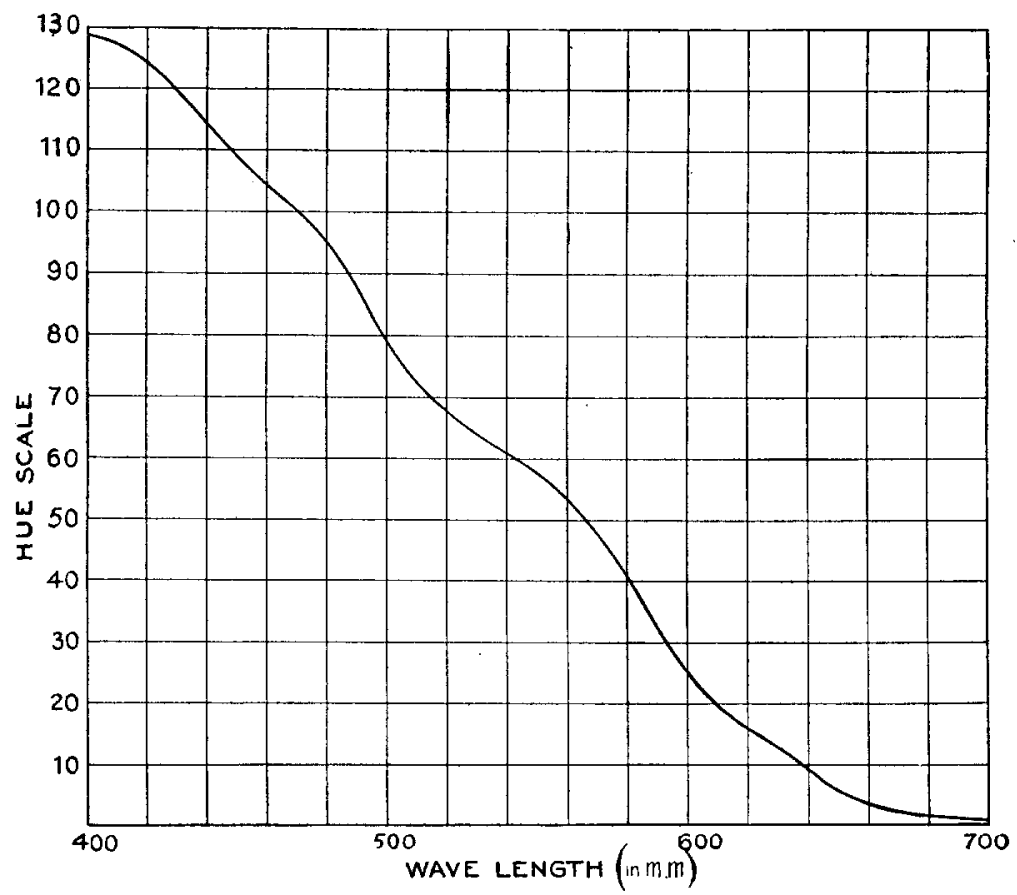

tained from the publisher, and it is entirely possible that some of these may differ slightly from those issued in Mr. Ridgway's book.

The colorimetric analyses of the 36 color standards of the hue scale are given in Table I (p. 507). They are numbered (column I) consecutively, starting with the reddest red and ending with the reddest purple. The names (column 2 ) are those proposed by Ridgway. The dominant hue values (column 3 ) are in milli-micnons $(\mu \mu)$ and the purity values (column 4 ) are in per cent. white or 
per cent. hue. In column 5 are given the wave-length intervals, $d \lambda$ (in $\mu \mu$ ), between the successive samples. In column 6 are given the values, in sensation units, of the corresponding intervals on the sensation scale, determined by use of the scale-reading curve.

The values in column 6 should be equal if the theoretical requirements of a uniformly grade sensation scale are fulfilled by the samples used. The amount of departure from uniformity in these values indicates the extent of failure in the fulfilment of the ideal conditions. The uniformity is quite good considering the practical difficulties encountered in the preparation of color standards.

Many more data are needed for the establishment of the hue sensibility curve of the average normal eye, observations on a larger number of different individuals being required.

TABLE $\mathrm{I}$.

\begin{tabular}{|c|c|c|c|c|c|}
\hline $\begin{array}{l}\text { I } \\
\text { No. }\end{array}$ & $\stackrel{2}{\text { Name }}$ & $\begin{array}{l}3 \\
\text { Hue }\end{array}$ & $\stackrel{4}{\text { Purity }}$ & $\begin{array}{c}5 \\
d_{\lambda}\end{array}$ & $\begin{array}{c}6 \\
d s\end{array}$ \\
\hline I & Spectrum Red & 633 & 55 & . & . \\
\hline 2 & & 616 & $3 I$ & 17 & 5.0 \\
\hline 3 & & 610 & 34 & 6 & 3.0 \\
\hline 4 & & 605 & 34 & 5 & 2.0 \\
\hline 5 & & $\cdots$ & . & . & 2.5 \\
\hline 6 & Orange Chrome & 597 & 40 & 8 & 2.5 \\
\hline 7 & & 595 & 34 & 2 & 1.5 \\
\hline 8 & & $\tilde{593}$ & 26 & 2 & I.5 \\
\hline 9 & & 589 & 23 & 4 & 3.0 \\
\hline Io & & 586 & $3^{I}$ & 3 & 3.0 \\
\hline I I & & 582 & 34 & 4 & 3.0 \\
\hline 12 & Lemon Yellow & 579 & 29 & 3 & 3.0 \\
\hline I3 & & 577 & 34 & 2 & 2.0 \\
\hline I4 & & 574 & 39 & 3 & 2.0 \\
\hline I5 & & 569 & 42 & 5 & 3.0 \\
\hline I6 & & 566 & 42 & 3 & 2.0 \\
\hline I7 & & 548 & 47 & I8 & 8.0 \\
\hline I8 & Emerald Green & 521 & 63 & 17 & 9.0 \\
\hline I9 & & $5 \mathrm{I} 8$ & 66 & 3 & 2.0 \\
\hline 20 & & 5IO & 63 & 8 & 3.5 \\
\hline $2 \mathrm{I}$ & & 495 & 55 & I5 & I0.0 \\
\hline 22 & & 490 & 54 & 5 & 5.5 \\
\hline 23 & & 486 & $5 \mathrm{I}$ & 4 & 3.0 \\
\hline 24 & & 484 & 73 & 2 & I. 5 \\
\hline
\end{tabular}




I
No.
25
26
27
28
29
30

\begin{tabular}{|c|c|c|c|c|c|}
\hline$\stackrel{2}{\text { Name }}$ & & $\begin{array}{c}3 \\
\text { Hue }\end{array}$ & $\begin{array}{c}4 \\
\text { Purity }\end{array}$ & $\begin{array}{c}5 \\
d_{\lambda}\end{array}$ & $\begin{array}{l}6 \\
\text { ds }\end{array}$ \\
\hline Spectrum & Blue & 479 & 70 & 5 & 2.5 \\
\hline & & 476 & 57 & 3 & 2.0 \\
\hline & & 470 & 62 & 6 & 3.0 \\
\hline & & 460 & 62 & IO & 4.0 \\
\hline & & 445 & 58 & I 5 & 8.0 \\
\hline Spectrum & Violet & 425 & 60 & 20 & 10.0 \\
\hline
\end{tabular}

Purples.

$$
\begin{aligned}
& 3 \mathrm{I} \\
& 32 \\
& 33 \\
& 34 \\
& 35 \\
& 36
\end{aligned}
$$

$\begin{array}{cr}22 & \ldots \\ \text { I5 } & \text { I I } \\ \text { I3 } & 4 \\ \text { I6 } & \text { I7 } \\ \text { II } & 6 \\ 9.4 & 22\end{array}$

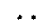

Colors Applied to Oil and Gas Storage Tanks. Anon. (Scientific American, vol. cxvi, No. 6, February 10, 19I7.)-In considering the effects of the different types of rays of which light is composed, the calorific or heat-producing rays are conducted by painted or finished objects in a widely varying degree, according to a paper by Henry A. Gardner, presented before the annual meeting of the Pennsylvania State Association of Master Painters and Decorators at Philadelphia. This fact, it is stated, should be studied by the contracting painter who is called upon to paint the enormous area presented by metal oil tanks. Such tanks may contain light distillates which, upon becoming warm, produce highly expansible vapors. When black or dark colored paints have been used, rapid absorption takes place, and considerable losses by evaporation are apt to occur. White or light colored paint should therefore be used for the finishing coat on oil storage tanks. Paints presenting a high gloss are, moreover, less absorptive of thermal rays than those presenting a duller surface.

The experiment was made of exposing a number of small tanks containing benzine, painted in various colors with a gloss finish, to the rays of a carbon arc for a period of 15 minutes. The rise in temperature of the benzine in degrees Fahrenheit was, for black paint, $54^{\circ} \mathrm{F}$; ; for light gray, $26.3^{\circ}$; for white paint, $22.5^{\circ}$; for aluminum paint, $20.5^{\circ}$; and for tin plate, $19.8^{\circ}$. Although plain tin, on account of its smooth, bright surface, gave the best results, it does not constitute a practical finish, as iron coated with tin corrodes unless protected with paint. Aluminum paint gave very good results, but it is not nearly so serviceable as lead and zinc linseed oil paint. 